\title{
Um espelho invertido da República: a correspondência dos diplomatas franceses no Brasil como objeto histórico (1892-I9Io)
}

[ An inverted mirror of the Republic: the correspondence of the

French diplomats in Brazil as historical object (I892-I9IO)

\author{
Sílvia Capanema P. de Almeida ${ }^{\mathrm{x}}$
}

Trabalho realizado com o apoio do programa USP-Cofecub.

RESUMO - $O$ artigo apresenta resultados do projeto de pesquisa sobre a correspondência diplomática dos franceses no Brasil na Primeira República. Explora-se um campo novo na história das relações internacionais, que são também nutridas pelos imaginários e trocas sociais, abordando a correspondência dos diplomatas como fonte de pesquisa e como objeto de estudo. Analisam-se dois elementos presentes na documentação: a polêmica sobre a autorização da emigração francesa para o Brasil entre I875 e I908 e a imagem da organização política brasileira na virada do século XIX para o XX. A República é vista através de um espelho invertido e forjado pelos ministros plenipotenciários ou cônsules franceses, que são também atores sociais plenos, com objetivos, estilos de escrita, opiniões e finalidades próprios. A Primeira República brasileira é compreendida como uma construção e uma representação ultrapassando as fronteiras nacionais. PALAVRASCHAVE - Primeira República; correspondência diplomática; relações França-Brasil; imaginários. - ABSTRACT - This article presents a part of the results of the research project on the diplomatic correspondence of the French in Brazil during the First Republic. It is intended to explore a new field in the history of international relations, which are also nourished by the imaginary and social exchanges, by approaching diplomats' correspondence as a source of research, and as an object of study. I will analyze two elements in the documentation: the controversy involving the authorization of French emigration to Brazil between I875 and I908 and the image of the Brazilian political organization in the late nineteenth and early twentieth centuries. The Republic is seen through a mirror inverted and forged by the French ambassadors or consuls, who are also full social actors with objectives, styles of writing, opinions and purposes. The First Brazilian Republic is understood as a construction and a representation that goes beyond national borders. - KEYWORDS - First Republic; diplomatic correspondence; France -Brazil relations; imaginary.

Recebido em I3 de junho de 2017

Aprovado em I7 de agosto de $20 \mathrm{I7}$

CAPANEMA P. DE ALMEIDA, Sílvia. Um espelho invertido da República: a correspondência dos diplomatas franceses no Brasil como objeto histórico (I892-I9Io). Revista do Instituto de Estudos Brasileiros, Brasil, n. 67, p. I65-I83, ago. 2017.

DOI: http://dx.doi.org/Io.II6o6/issn.23I6-90IX.voi67pI65-I83

I Université Paris I3 - Sorbonne Paris Cité (Paris, França). 
O interesse pela correspondência diplomática de franceses no Brasil surgiu no contexto da minha tese de doutorado. Morando na França e buscando fontes alternativas para estudar um acontecimento no Brasil - a revolta dos marinheiros de I9IO $^{2}-$, fui pesquisar nos arquivos diplomáticos que se encontravam então no Quai d'Orsay ${ }^{3}$. Para minha alegria e surpresa, a documentação encontrada era de grande riqueza e contribuiu de forma excepcional para os resultados da minha reflexão. As missivas demonstraram a importância da revolta dos marujos brasileiros em seu tempo e também como os diplomatas franceses construíam sua própria visão e análise dos fatos brasileiros, geralmente inspirados em seu imaginário e representação do país. A questão racial, lida sob o prisma do olhar imperialista, emergia nos escritos dos diplomatas, que traziam informações complementares sobre a revolta, até mesmo porque o chargé d'affaires francês no Rio de Janeiro encontrava-se a bordo de um navio na baía da Guanabara na noite do 22 de novembro, quando a revolta começou. Em uma longa carta, o diplomata relata ao ministro francês os acontecimentos e suas impressões 4 . Essa correspondência também se mostrou uma fonte complementar para se compreenderem os interesses internacionais militares e navais, as encomendas da Marinha brasileira e as rivalidades francesas com outros países europeus, como a Inglaterra e a Alemanha em particular5. No entanto, para além dessas dimensões, a documentação me impressionou pela riqueza dos relatos e

2 CAPANEMA P. DE ALMEIDA, S. “Nous, marins, citoyens brésiliens et républicains?”: identités, modernité et mémoire de la révolte des matelots de I9Io. Tese (Doutorado em História). École des Hautes Études en Sciences Sociales: Paris, 2009.

3 Archives du Ministère des Affaires Étrangères (Amae). Hoje os arquivos se encontram no Centre des Archives Diplomatiques de La Courneuve. FRANCE Diplomacie. Centre des Archives Diplomatiques de La Courneuve. Disponível em: <http://www.diplomatie.gouv.fr/fr/archives-diplomatiques/acceder-aux-centresdes-archives-diplomatiques/site-de-paris-la-courneuve >. Acesso em I2/6/20I7.

4 Petrópolis, carta do chargé d'affaires Lacombe ao ministro das Relações Exteriores Stephen Pichon. Archives du Ministère des Affaires Etrangères (Amae). Correspondance politique et commerciale, politique Interieure - Immigration, v. 6, 28/II/I9IO.

5 CAPANEMA P. DE ALMEIDA, S. A modernização do material e do pessoal da Marinha nas vésperas da revolta dos marujos de I9Io: modelos e contradições. Estudos Históricos, Rio de Janeiro, v. 23, p. I47-I69, 2010. 
suas formas. Interessante ver o modo como os correspondentes franceses abordavam a política, os homens políticos e a sociedade brasileira. Os testemunhos são com frequência pejorativos, caricaturais, mas também ricos em detalhes "esquecidos" ou "poucos conhecidos" da historiografia. As cartas, missivas, documentos, constituem uma espécie de "wikileaks ${ }^{6}$ do passado", com informações que podem modificar a própria interpretação da história. Como os de hoje, os diplomatas do início do século passado escreviam revelações "secretas", mas também julgamentos de valor, considerações, textos carregados de adjetivos, alguns com esforços de estilo para chamar a atenção de seus destinatários.

Na maior parte das abordagens e estudos, a correspondência diplomática é tomada como fonte e não como objeto. Ela é estudada como "uma fonte a mais" para a análise de certo objeto histórico. Ainda são raras as publicações que oferecem edições comentadas de documentos oriundos da correspondência diplomática7. Alguns estudos recentes já os consideram, todavia, como objeto privilegiado, como os trabalhos de Juliette Dumont, sobre a diplomacia cultural francesa na América Latina nos anos I930 e I940, e os de Cláudio Antônio Santos Monteiro, que apresenta uma análise longa sobre a correspondência diplomática para compreender a interpretação francesa do fim do Império e do início da República (anos I850-I89I) ${ }^{8}$. Nessas e em outras análises, a documentação é de extrema relevância para se compreenderem os processos internos que motivam as tomadas de decisões, bem como a criação dos imaginários culturais, que em muitos dos casos são estruturas de longa duração que conduzem as relações diplomáticas para além das representações oficiais entre os países. Seguindo Robert Frank, é preciso pensar as relações internacionais não somente como um affaire entre Estados, ou ainda negociações restritas ao mundo comercial, mas como uma dimensão existente na vida cotidiana, nas relações sociais e entre os imaginários populares`. Nesse sentido, uma leitura atenta da correspondência diplomática revela que as cartas e missivas não tratam unicamente de relações "objetivas" entre Estados, mas vão bem além. Os documentos revelam jogos de interesse e de opinião, relatos sobre experiências pessoais na função diplomática, olhares e impressões, representações reveladoras de dinâmicas sociais complexas.

O presente artigo se inscreve nessa perspectiva de avançar na compreensão dos processos históricos através da transformação do estatuto da correspondência

6 Assim como o Wikileaks (https://wikileaks.org), esses documentos são fonte de informações confidenciais referentes a ações diplomáticas.

7 Como, por exemplo: RAYMOND, J.-F. de (Org.). Arthur de Gobineau et le Brésil: correspondance diplomatique du ministre de France à Rio de Janeiro, I869-I870. Grenoble: Presses Universitaires de Grenoble, I990.

8 DUMONT, J. Le Brésil et l'Institut International de Coopération Intellectuelle (I924-I946): le pari de la diplomatie culturelle. Paris: Éditions de l'IHEAL, 2009; MONTEIRO, C. A. S. France et Brésil: de l’Empire à la République (I850-I89I). Tese (Doutorado em História). Strasbourg: Université Robert Schuman, 2006.

9 Entre outros: FRANK, R. Images, imaginaire et Europe: présentation. In: GIRAULT, R.G. (dir.). Identité et conscience européennes au XXe siècle. Paris: Hachette, I994; FRANK, R. Altérité, représentations de l'Autre. In: DELPORT, C.; MOLIER, J.-Y.; SIRINELLI, J.-F. (Dir.). Dictionnaire d'histoire culturelle de la France contemporaine. Paris: PUF, 20IO. 
diplomática: de fonte a objeto. Para tanto, analisei os documentos conservados nos Archives du Ministère des Affaires Étrangères - AMAE (Arquivos do Ministério das Relações Exteriores), abrangendo a correspondência política e comercial entre I892 e I9I0. Esses documentos encontravam-se nos volumes da coleção "Brésil. Politique intérieure. Immigration” ${ }^{\text {ro }}$. São milhares de páginas de correspondência, geralmente cartas manuscritas, com bela caligrafia, às vezes datilografadas, assinadas por cônsules instalados em diferentes cidades brasileiras (Petrópolis, São Paulo etc.) e pelo ministro plenipotenciário no Rio e destinadas ao ministro das Relações Exteriores na França. Encontram-se também manuscritos, cartas de resposta, correspondência mais formal entre ministros (do comércio, de relações internacionais, do interior), muitas delas provavelmente escritas por colaboradores do gabinete e assinadas pelos ministros, cópias de documentos, respostas de diplomatas franceses domiciliados em outras cidades, recortes de imprensa, rascunhos. As cartas são escritas em francês ou traduzidas para esse idioma, contendo às vezes termos afrancesados, como cidade de Saint Paul e palavras em português entre aspas, como "fazendeiros" ou "fazenda".

Neste artigo, colocarei em evidência duas dimensões: a polêmica sobre a questão da interdição da emigração de franceses para o Brasil até a supressão dessa medida em I908 e a visão que os diplomatas franceses tinham sobre a forma de se fazer política no Brasil. Esses elementos participam da construção de uma representação da República brasileira e, mais do que isso, colaboram para pôr em causa a sua legitimidade. Atores políticos da Terceira República na França (I870-I940), particularmente em um momento em que a República francesa se reforça, se democratiza e se radicaliza ${ }^{\mathrm{II}}$, esses correspondentes enxergam o Brasil através do olhar de seu tempo, com seus limites, mas também seguindo interesses, prestígios e repertórios pessoais que terão consequências para determinadas decisões políticas num sistema de trocas culturais. Escrever sobre a política no Brasil, no contexto, é também uma forma de buscar entender como o sistema republicano se desenvolve nos trópicos. Os diplomatas enxergam através de suas categorias, representações e realidades, como se olhassem para um espelho cuja imagem refletida é o contrário do que desejam ou esperam ver. Mais do que isso, enxergam uma república disfuncional e que incomoda, vista ora com desdém, ora com cobiça, de acordo com suas ambições e referências de atores sociais.

\section{A proibição da emigração francesa para o Brasil}

A interdição - ou não - da emigração francesa organizada por agências brasileiras é talvez uma das maiores preocupações dos diplomatas na documentação estudada. Essa proibição já foi tratada pelos historiadores Mônica Leite Lessa e Hugo Rogélio Suppo em artigo que utiliza em grande parte a correspondência do Ministério das

IO Um levantamento sobre essa documentação encontra-se em: EVEN, P. Guide des sources de l'histoire du Brésil aux archives du ministère français des affaires étrangères. Paris: Editions de 1'IHEAL, 1987.

II Sobre o contexto, ver, entre outros: REBERIOUX, M. La République radicale? 1898-1914. Paris: les éditions du Seuil, 1975. (Coll. Points Histoire.); DUCLERT, V. La République imaginée - 1870-1914. Paris: Belin, 2010. 
Relações Exteriores francês ${ }^{\mathrm{I} 2}$. Lessa e Suppo demonstram que a proibição - estabelecida pela chamada "circular de Meaux" de I875 e seguindo a determinação de outros países, como Itália e Alemanha - é constantemente criticada pelos diferentes ministros plenipotenciários em razão de seus interesses comerciais com o Brasil. De fato, como relatam os próprios diplomatas, entre I875 e I908 a França passa de segundo a quinto principal parceiro comercial do Brasil ${ }^{\text {s3 }}$. Os diplomatas argumentam que a supressão dessa interdição melhoraria a relação entre os dois países e daria maior impulso às relações comerciais, já que a França teria todo interesse em constituir uma elite de emigrantes estabelecida no Brasil. Isso contribuiria também para evitar mal-entendidos sobre a boa vontade do governo francês com relação ao Brasil. A França, no contexto, não era considerada um país com risco de grande emigração devido à sua composição demográfica e necessidade de mão de obra no próprio país.

A partir dessa leitura, convém estudar com mais atenção as tensões realmente envolvidas nesse debate sobre a proibição da imigração ou sua revocação para os franceses na virada do século XIX para o XX, partindo das observações presentes na escrita dos diplomatas, que revelam o íntimo das relações entre os dois países.

No dia 5 de fevereiro de I892, o ministro plenipotenciário da França no Rio, Auguste Gérard, escreve ao ministro das Relações Exteriores francês para interrogá-lo sobre a recondução da circular de I875, que proibia a emigração através das agências oficiais para o Brasil. Evocando a possibilidade de revocá-la, ele condiciona: "vossa excelência estima que seria preciso subordinar essa medida ao estabelecimento com o Brasil de um regime comercial próprio que satisfaça nossas indústrias de exportação" ${ }^{14}$.

O mesmo diplomata, em uma carta despachada posteriormente e datada de Io de outubro de I892, comenta uma lei que estava sendo elaborada no Brasil para autorizar a imigração de asiáticos, japoneses e chineses. Ele revela claramente outros fatores que constrangeriam a aceitação da liberação da viagem de trabalhadores europeus ao Brasil. Com efeito, o recente passado escravocrata brasileiro ainda estaria bem presente na memória e na estrutura social e se relacionaria com a superioridade ou inferioridade racial dos povos:

O Brasil aboliu a escravidão, mas ele se negou a modificar o regime de propriedade e de cultura. Ele não foi capaz de organizar o trabalho livre na pequena propriedade através, ao mesmo tempo, da atração e da sanção... Será que está procurando agora com os chineses aquilo que não conseguiu encontrar na Europa: substitutos para a escravidão?'5.

I2 LESSA, M. L.; SUPPO, H. R. A emigração proibida: o caso França-Brasil entre I875 e I908. In: LUCA, T. R. de; VIDAL, L. (Org.). Franceses no Brasil: séculos XIX-XX. São Paulo: Unesp, 2009, p. 67-Io3.

I3 Ibidem, p. 96.

I4 Rio de Janeiro, carta do ministro plenipotenciário Auguste Gérard ao ministro das Relações Exteriores Alexandre Ribot. AMAE, Brésil. Politique intérieure. Immigration, v. I, 5/2/I892, f. 2. As traduções de extratos da correspondência presentes neste artigo foram feitas por mim.

I5 Rio de Janeiro, carta do ministro plenipotenciário Auguste Gérard ao ministro das Relações Exteriores Alexandre Ribot. AMAE, Brésil. Politique intérieure. Immigration, v. I, Io/Io/I892, f. 8. 
É sabido que o debate sobre a vinda de imigrantes asiáticos ao Brasil envolvia também a dimensão racial, dentro da leitura determinista em voga na época e da hierarquia de raças. A hipótese da introdução de imigrantes chineses foi barrada em razão de uma presumida inferioridade cultural e racial ${ }^{16}$, enquanto a imigração japonesa será uma solução encontrada a partir de I908. Interessante ver que a visão da hierarquia de raças também estava presente na interpretação dos franceses, como fica evidente em outro trecho da mesma carta:

A experiência, por outro lado, até hoje, quer nas Îndias holandesas, quer no Peru, quer mesmo nas nossas próprias colônias da Martinica e da Reunião, demonstra que o imigrante chinês é de um valor medíocre para a agricultura em geral, nomeadamente para a cultura do café, sobretudo nas montanhas ${ }^{\mathrm{T}}$.

Anexa a esse mesmo correio, encontra-se uma cópia de um artigo do Daily Telegraph denunciando as condições de vida dos imigrantes no Brasil. Em 5 de dezembro do mesmo ano, o mesmo correspondente do Rio de Janeiro retoma essa linha de argumentos em outra carta:

A ideia que, depois da abolição da escravidão (I3 de maio de I888), deu sequência à propaganda brasileira a favor da imigração deve provocar decepções. O Brasil não procurava com a imigração nada mais do que um substituto livre para o escravo. $O$ imigrante desembarcado no Brasil encontrava trabalho e salário: mas a esperança da propriedade lhe continuava quase que proibida. Pois não havia, mesmo no Império, e não há, sobretudo, depois da Revolução Federativa de I889, nenhuma terra que o Estado possa dar ou vender aos emigrantes. $E$ quanto às grandes propriedades particulares, o "Fazendeiro" [em português no original] não consente em dividi-las ou parcelá-las [...] A França, aliás, não detém sozinha o privilégio das medidas de precaução contra a emigração para o Brasil. A maior parte dos governos europeus a seguiram nessa via. E o próprio governo brasileiro também se resignou, já que é às raças da Ásia que ele pede hoje braços para a cultura do cafér ${ }^{18}$.

Essa correspondência era destinada ao ministro das Relações Exteriores, mas não unicamente a ele, uma vez que uma nota do ministro do Comércio, da Indústria e das Colônias encontra-se anexa à documentação, assinalando a recepção do relatório do ministro da França no Rio relativo à questão da emigração ao Brasil (nota de 27/I/I893).

Mas a questão estava longe de ser decidida. A troca epistolar entre os ministros e os correspondentes no Brasil é contínua, atestando a existência de uma polêmica que

I6 COSTA, E. V. da. Da monarquia à república - momentos decisivos. São Paulo: Unesp, I999; COSTA, E. V. da. Da senzala à colônia. São Paulo: Unesp, I998.

I7 Rio de Janeiro, carta do ministro plenipotenciário Auguste Gérard ao ministro das Relações Exteriores

Alexandre Ribot. AMAE, Brésil. Politique intérieure. Immigration, v. I, Io/Io/I892, f. 8.

I8 Ibidem. 
exprime as pressões brasileiras, mas também dos diplomatas e cônsules no Brasil, pela derrogação da interdição, como se verá a seguir.

No dia I3 de agosto de I894, uma nota do Ministério das Relações Exteriores em Paris (subdireção dos affaires consulares) é enviada ao ministro plenipotenciário no Rio sobre as razões segundo as quais se mantém a interdição da emigração francesa para o Brasil. A carta, bem mais objetiva e pragmática, provavelmente ditada ou escrita em grande parte por um assessor do gabinete do Ministério, afirma antes de tudo que a circular de I875 não proíbe a emigração francesa para o Brasil dos colonos que desejam partir de forma individual, expondo-se "aos riscos e perigos". E mais adiante: "Essa circular proíbe somente as agências de imigração autorizadas a exercer sua indústria na França e proceder ao recrutamento e engajamento de emigrantes destinados às províncias brasileiras"ז9.

A partir desse documento, descobre-se que desde I877 o governo francês indicou que estava pronto a revocar a proibição da emigração francesa para o Brasil particularmente sob as seguintes condições: haver um visto com contrato detalhando os engajamentos do empregador e a intervenção das autoridades brasileiras para facilitar aos emigrantes o despacho de seus passaportes e contratos no consulado francês. Acrescenta-se ainda: "nós temos interesse, a partir de então, em comunicar ao gabinete do Rio que estaremos dispostos a mostrar-nos conciliadores em matéria de emigração no caso em que ele consentir em abaixar, em favor de alguns de nossos produtos, suas tarifas alfandegárias”20.

Assim, percebe-se que a polêmica envolvia também - algo comum nas negociações políticas - o uso das relações de força por parte das autoridades francesas que, caso revocassem a interdição, não o fariam gratuitamente. Exigiam melhorias no processo de emigração, mas também favorecimentos comerciais.

\section{Colonos, ativos agentes de exportação}

É com a entrada do consulado de São Paulo nas trocas epistolares que a polêmica ganha uma nova dimensão. Por um lado, o cônsul instalado nessa capital de estado fornece novos elementos e informações bem mais detalhados, mas também mais positivos sobre a condição dos imigrantes. Por outro lado, a presença de um chargé de mission em São Paulo, Charles Weiner, que chega ao Brasil em I896, mudará definitivamente o tom das trocas epistolares. Charles Weiner se mostrará claramente favorável se não à emigração francesa para o Brasil, pelo menos à revogação definitiva da circular de I875.

Nessa medida, o cônsul Georges Ritt escreve em uma missiva de 9 de agosto de I895, depois de descrever as diferenças entre os imigrantes que se encontram no Brasil:

I9 Paris, S/A, nota do Ministério das Relações Exteriores ao ministro plenipotenciário Antoine Imbert. AMAE,

Brésil. Politique intérieure. Immigration, v. I, I3/8/I894, f. 50.

20 Ibidem. 
O Brasil, com efeito, dentre todas as regiões da América do Sul, é ainda aquela onde o emigrante inteligente e ativo pode melhor, mais rápido e mais seguramente, se não fazer fortuna, pelo menos melhorar sensivelmente sua situação e assegurar seu futuro [...]. Infelizmente, enquanto em todas as outras partes do mundo a população é espremida e superabunda em um solo desgastado por excesso de produções e incapaz de retribuir o trabalho incessante dos habitantes e de alimentá-los, o Brasil aparece até aqui como culpado perante a humanidade não tendo feito todos os esforços desejados para povoar e explorar essas imensas terras [...] é, no entanto, uma das faces da questão da imigração cuja importância é enorme e não pode deixar de atrair toda a atenção dos homens de Estado, sobretudo agora que, avançando a passos largos, o socialismo se impõe, apesar da resistência desesperada das velhas organizações sociais, e, em um tempo mais ou menos próximo, acarretará reformas radicais na constituição da família, bem como na das relações sociais e da relação do trabalho com o capital. [...] o estado de São Paulo parece ser o que menos mal compreendeu o problema ${ }^{21}$.

Interessante essa menção do diplomata ao "socialismo" como uma doutrina do progresso, exemplo que não é comum no corpus analisado. Se conhecemos a ação de vários mediadores franceses na introdução das ideias socialistas e progressistas no Brasil nos séculos XIX e $\mathrm{XX}^{22}$, no entanto, nas fontes estudadas, essa não parece ser a opção dos diplomatas, pelo menos de forma assumida. Há um silêncio sobre a questão, mas seria preciso analisar a mesma documentação em um intervalo de tempo mais longo para tentar compreender e afirmar - ou não - esse silêncio e as menções feitas às correntes políticas e ideológicas da época. De toda forma, o meio diplomático parece reticente ou "reservado" sobre o assunto. O ministro das Relações Exteriores em Paris decide, por sua vez, escrever ao ministro do Comércio, da Indústria, dos Correios e Telégrafos para que ele possa julgar se não seria oportuno transmitir a análise do cônsul de São Paulo, Georges Ritt, às companhias de navegação francesas. A resposta do ministro do Comércio, numa carta de Paris endereçada a seu "caro colega” em 2I de fevereiro de I896, é categórica:

Como sabe, é atualmente proibido a nossos agentes de emigração recrutar e embarcar emigrantes franceses com destino ao Brasil. Essa interdição deve durar enquanto a situação dos emigrantes no Brasil não for modificada, e que os nossos egressos nacionais não tiverem obtido as garantias que nós inúmeras vezes pedimos em seu favor. [...] Nessas condições, não me parece haver, pelo momento, grande interesse em comunicar às Companhias de navegação o relatório do nosso cônsul23.

2I São Paulo, carta do cônsul Georges Ritt ao ministro das Relações Exteriores Gabriel Hanotaux. AMAE, Brésil. Politique intérieure. Immigration, v. I, 9/8/1895, f. 67.

22 Ver, entre outros: PONCIONI, C. Pontes e ideias - Louis-Léger Vauthier, um engenheiro fourierista no Brasil. Recife: Companhia Editora de Pernambuco, 20Io; LUCA, T. R. de; VIDAL, L. (Org.). Franceses no Brasil: séculos XIX-XX. São Paulo: Unesp, 2009.

23 Paris, carta do ministro do Comércio, da Indústria, dos Correios e Telégrafos Gustave Mesureur ao ministro das Relações Exteriores Marcellin Berthelot. AMAE, Brésil. Politique intérieure. Immigration, v. I, 2I/2/I896, f. IO2. 
O chargé de mission Charles Weiner não hesita, no entanto, em insistir na revocação da interdição. Em uma carta enviada de Santa Catarina, em I6 de agosto de I896, analisando a situação dos colonos alemães, que seriam 2.500 em Curitiba e 4.000 no interior do estado de Santa Catarina, na maioria comerciantes, ele diz:

A prosperidade desse grupo é grande. Vários colonos são milionários em marcos. Sem mobilizar os capitais da Europa, eles fundaram em seu país de adoção importantes manufaturas de tecido de algodão, de chapelaria, de fósforos, cervejarias etc., etc.

Seria desejável que a lei francesa permitisse a nossos nacionais participar dos benefícios que se encontram em alguns estados do Brasil, como as condições econômicas e a riqueza do solo, em um clima salubre ${ }^{24}$.

A mesma visão não é compartilhada pelo cônsul de São Paulo. Em uma missiva datada de Io de junho de I896, ele explica de que forma respondeu a uma solicitação de Campos Sales, à época presidente do estado de São Paulo, feita aos cônsules de diversas nações europeias para pedir a facilitação da emigração de cidadãos de seus países: "Eu me mantive no domínio das considerações meramente gerais, me exprimindo todavia com uma franqueza ainda maior na medida em que nosso país, de onde os habitantes não emigram e não têm interesse em emigrar, encontra-se absolutamente desinteressado na questão"25.

Mas, sob insistência de Campos Sales, homem político particularmente bem apreciado pelos correspondentes franceses, o enviado especial ao Brasil, Charles Wiener, escreve ao ministro das Relações Exteriores uma carta bem mais clara e ainda mais favorável à suspensão da interdição da emigração, em I4 de junho de I896. Seria interessante retomá-la quase em sua integralidade:

Afora diversas causas econômicas, uma razão de ordem política pesa sobre nosso comércio no Brasil. Há 20 anos, esse país é objeto de uma medida de exceção; nosso governo proibiu a imigração francesa para lá.

Esse ostracismo, atingindo o amor-próprio da nação brasileira, tem motivado, em contrapartida, uma má vontade constante cujos efeitos desagradáveis se pode a todo momento constatar ${ }^{26}$.

Uma nota de rodapé desse mesmo documento que está em sequência indica que os navios de guerra Tamandaré, Riachuelo e outros, estragados na "revolução" (proclamação da República) foram consertados na Bélgica por um montante não longe

24 Santa Catarina, carta do chargé de mission Charles Weiner ao ministro das Relações Exteriores Léon Bourgeois. AMAE, Brésil. Politique intérieure. Immigration, v. I, I6/4/I896, f. I08A.

25 São Paulo, carta do cônsul Georges Ritt ao ministro das Relações Exteriores Gabriel Hanotaux. AMAE, Brésil. Politique intérieure. Immigration, v. I, I/6/I896, f. I30.

26 Paris, carta do chargé de mission Charles Wiener ao ministro das Relações Exteriores Gabriel Hanotaux. AMAE, Brésil. Politique intérieure. Immigration, v. I, I4/6/I896, f. I47. 
de I milhão de francos, valor bem mais elevado que o estimado pelos fabricantes franceses. A escolha dos belgas deveu-se ao fato de não se querer "auferir um lucro por menor que seja, - a um estaleiro francês...”27. Em seguida, a carta continua:

O senhor Campos Sales, antigo "líder" da câmara, presidente do Estado de St. Paul, me disse: [e cita, segundo a nota, a minuta n. 132 de 6 de março de I896]: "Sabemos que o francês não é emigrante. Os gostos o fixam em seu país de origem, cuja prosperidade não impõe as necessidades de expatriação, às quais se atribuem as migrações italianas, alemãs etc. Nós não teríamos de contar com ele como colono, e a França não teria a temer seu êxodo para nossos territórios. Mas, do ponto de vista moral, seria necessário e urgente mesmo retomar o dispositivo ao qual eu me refiro para fazer desaparecer o estado de mal-estar que alcançam as relações franco-brasileiras e para destruir a lenda relativa à pretendida antipatia da França com relação ao Brasil” [fim da citação]. Não vou insistir aqui sobre as vantagens que obtêm as nações concorrentes da imigração de seus nacionais nas regiões centrais e meridionais dessa república: a maioria de um milhão de italianos e a quase totalidade dos 200 mil alemães encontraram ali uma forma de criar uma existência abastada. Os colonos tornaram-se ativos agentes de exportação de seus países de origem ${ }^{28}$.

No entanto, as solicitações de Charles Wiener não serão atendidas de imediato. A interdição da emigração com contrato para o Brasil - o que, não se confunda, não impedia a emigração de fato - somente será retirada mais de uma década depois, em I908. A atividade de um diplomata em particular, Stephen Pichon, pode ter contado bastante para a supressão, enfim, da interdição. Em I907, Stephen Pichon, que foi ministro plenipotenciário no Rio de Janeiro, torna-se ministro das Relações Exteriores da França. Seus conhecimentos do país, redes sociais e experiência podem ter contribuído para que visse com um olhar mais favorável, uma vez ministro estabelecido na capital francesa, a demanda dos diplomatas franceses no Brasil.

De fato, Stephen Pichon (I857-I933) foi um jornalista, político e diplomata republicano radical, membro do partido radical-socialista. Considerado como homem de esquerda radical, ele também é reconhecido como ativista da separação do Estado e da Igreja, chegando a pertencer à corrente anticlerical francesa. Foi deputado, senador e ministro das Relações Exteriores. Foi ministro plenipotenciário no Brasil entre I895-I897 ${ }^{29}$.

No dia 22 de maio de I908, Albert-François-Ildefonse d'Anthonard, ministro plenipotenciário da França no Brasil enviado em I907, escreve a Stephen Pichon

\section{Ibidem.}

28 Ibidem.

29 Ver: PICHON Stephen. Ancien sénateur du Jura. Disponível em: <https://www.senat.fr/senateur3eme-republique/pichon_stepheno429r3.html〉. Acesso em: I2 jun. 20I7. Em outro trabalho, analisarei exclusivamente a ação desse diplomata no Brasil, sobretudo no que concerne a sua leitura sobre Canudos e também a seu papel na negociação da fronteira com a Guiana Francesa, temas que merecem um estudo à parte que ultrapassa os objetivos do presente artigo. 
pedindo explicitamente a modificação da circular de I875 por uma autorização condicional ${ }^{30}$. Após uma série de trocas epistolares entre ministros e representantes franceses na Alemanha e Itália, o ministro do Interior dará, finalmente, o seu acordo para a modificação. Em 6 de junho de I908, o ministro do Comércio comunica ao ministro das Relações Exteriores que o ministro do Interior e presidente do Conselho, Georges Clemenceau, não é contra a modificação da circular, e uma nova circular, de 4 de julho de I908, autoriza o recrutamento de emigrantes franceses com destino ao Brasil. Em II de fevereiro de I909, o ministro do Interior escreve ao ministro das Relações Exteriores para informá-lo sobre a partida de famílias de emigrantes franceses que embarcam no porto de Marselha em I6 de dezembro de I908. São 23 homens, I8 mulheres e 2I crianças menores de I5 anos. A partida se concretiza segundo uma demanda das famílias, que leem no jornal "um anúncio de uma imigração gratuita para o Brasil” 3 . São agricultores que se instalam a quatro horas e meia de caminho de ferro do Rio de Janeiro.

A longa polêmica diplomática e interministerial, analisada do ponto de vista da correspondência entre diplomatas e ministros, possibilita pensar tanto nos imaginários construídos sobre o Brasil, como nas relações de forças entre os países, em que a hegemonia francesa busca sempre se afirmar numa relação diplomática assimétrica. No entanto, a troca de cartas entre diferentes correspondentes permite também entender os interesses comerciais, políticos e as ações de diversos atores que exercem poderes e influências diferentes num mesmo contexto.

\section{O QUAdRo Político: A REPÚblica EM QUESTÃo}

Um segundo elemento a ser destacado a partir do corpus estudado diz respeito à imagem que os correspondentes franceses elaboravam do mundo político stricto sensu no Brasil. Essa imagem é certamente bem distante da visão que a República brasileira desejaria ter aos olhos da República francesa, um dos modelos para o sistema brasileiro ${ }^{32}$. Os diferentes correspondentes são bastante céticos quanto ao processo político brasileiro e suas consequências sociais e econômicas. Algumas simpatias eram, contudo, possíveis.

Os diplomatas franceses são bastante críticos com relação às instituições brasileiras, muito frágeis aos seus olhos. Como vem demonstrando a historiografia, o processo político da Primeira República brasileira se caracterizava pelas alianças entre grupos, partidos e estados de maior poder, que garantissem a estabilidade política e os interesses

30 Paris, carta do ministro plenipotenciário Albert-François-lldefonse d Anthonard ao ministro das Relações Exteriores Stephen Pichon. AMAE, Brésil. Politique intérieure. Immigration, v. IV, 22/5/ 1908, f. 74.

3I Paris, carta assinada pelo diretor da administração geral em nome do presidente do Conselho e ministro do Interior Georges Clemenceau ao ministro das Relações Exteriores Stephen Pichon. AMAE, Brésil. Politique intérieure. Immigration, v. IV, II/2/I909, f. I25.

32 Sobre esse "modelo" francês, real, imaginado ou mesmo "invertido", ver: LUCA, T. R. de; VIDAL, L., op. cit.; CAPANEMA, S.; COMPAGNON, O.; FLECHET, A. Os franceses não tomam banho? Imagens e imaginário da França no Brasil (séculos XIX-XXI). Rio de Janeiro: Fundação Casa de Rui Barbosa/ 7 Letras, 2017 (no prelo). 
econômicos de uma elite agroexportadora, através de uma aparente legitimidade ${ }^{33}$. Claro que a República significou transformações, novas simbologias, novos espaços para uma demanda de cidadania - o que de fato ocorria, mesmo se de forma diferente, com a participação popular em revoltas e a crescente presença do povo em protestos públicos nas praças, ruas ${ }^{34}$-, a separação entre igreja e Estado, mas também foi alvo de críticas, pois frustrou as expectativas, reconduziu a exclusão e era repleta de contradições ${ }^{35}$.

Em uma carta de 30 de janeiro de I896, o já citado cônsul de São Paulo, Georges Ritt, escreve sobre as eleições à presidência do estado, que deveriam acontecer em poucos dias. Ele coloca em evidência os méritos do candidato Campos Sales, do "dito partido Republicano", bom orador e político que transmitia uma imagem de conciliação. Segundo o diplomata, "não se pode desejar, pelo interesse geral do país, que ele cumpra as promessas contidas em sua profissão de fé” 36 .

Num contexto em que as eleições eram feitas pelo sufrágio universal masculino e com a exigência de obtenção de $2 / 3$ dos votos pelos candidatos, caso contrário a decisão caberia ao Congresso, o cônsul de São Paulo acrescenta:

Como vossa excelência pode constatar, há nessas disposições da Constituição Paulista, um sistema bastante original, que merece ser assinalado ao Departamento. Eu acrescentaria que, na circunstância, não haverá razão para se recorrer [ao voto indireto] pois nenhuma candidatura séria se opõe à de C. Sales para a presidência e de PeixotoGomide, atual presidente do Senado, para a vice-presidência do Estado ${ }^{37}$.

No contexto em que a presença de militares ainda era bastante sentida, o chargé d'affaires no Rio, em uma carta ao ministro de 24 de março de I896, interroga se:

[...] é permitido se questionar sobre a atitude dos militares que intervêm na política e a do governo que, aceitando tal intervenção, faz correr à nação riscos ainda maiores que a propaganda monarquista. Em todo caso, a República brasileira não parece ainda

33 VISCARDI, C. O teatro das oligarquias: uma revisão da "política do café com leite". Belo Horizonte: C/Arte, 200I; LESSA, R. A invenção republicana: Campos Sales, as bases e a decadência da Primeira República brasileira. 3. ed. revista e aumentada Rio de Janeiro: Top Books, 2015.

34 MELLO, M. T. C. A República consentida: cultura democrática e científica no final do Império. Rio de Janeiro: FGV/Editora da UFRJ, 2007; MATTOS, H. A vida política. In : SCHWARCZ, L. M. (Dir.). História do Brasil nação. A abertura para o mundo, I889-I930. Rio de Janeiro: Objetiva, 20I2, p. 84-I3I.

35 CARVALHO, J. M. de. Os bestializados: o Rio de Janeiro e a República que não foi. São Paulo: Companhia das Letras, I987; DELGADO, L. de A; FERREIRA, J. (Org.). O Brasil republicano. Volume I. O tempo do liberalismo excludente: da Proclamação da República à Revolução de I930. Rio de Janeiro: Civilização Brasileira, 2006,

36 São Paulo, carta do cônsul Georges Ritt ao ministro das Relações Exteriores Marcellin Berthelot. AMAE, Brésil. Politique intérieure. Immigration, v. I, 30/I/I896, f. 93.

37 Ibidem. 
curada dessa doença comum na América do Sul e com a qual ela se contaminou em seu nascimento ${ }^{38}$.

A referência à tomada de poder pelo marechal Deodoro da Fonseca (I889-I89I) e em seguida por Floriano Peixoto (I89I-I894) está presente nas entrelinhas desse trecho, e vê-se que os diplomatas temiam ainda mais a República da espada que a presença dos monarquistas como elemento perturbador da estabilidade política no Brasil39.

Para além da questão das eleições do estado de São Paulo, alguns relatos deixam transparecer as simpatias e boas relações que poderiam existir entre alguns homens políticos locais e diplomatas e a necessidade de causar boa impressão. Em carta de 23 de abril de I896, Georges Ritt evoca que o novo presidente do estado de São Paulo, Campos Sales, "não perde uma ocasião de falar de seus sentimentos de profunda simpatia pela França, onde ele, aliás, viveu por bastante tempo [...]"'40. Os esforços de diplomacia do país estariam dando bons resultados, pois havia um "reavivamento" das simpatias pela França, em razão, por um lado, da missão "pacífica e conduzida de forma bem-sucedida” pelo já citado Charles Wiener e, por outro lado,

[...] pela chegada oportuna de Stephen Pichon, o novo ministro da República, cujo discurso, à ocasião da apresentação de sua carta credencial, foi reproduzido em todos os jornais e causou, ao que sou capaz de julgar, a mais excelente impressão na opinião brasileira, bem como no espírito de seus compatriotas ${ }^{4}$.

O cônsul em São Paulo, Georges Ritt, escreve uma nova carta ao ministro em 3 de maio de 1896 para informá-lo de seus esforços incomensuráveis para tornar a França um país atrativo para os brasileiros; esforços medidos em cada detalhe. Assim, buscava impressionar e chamar atenção para suas iniciativas pessoais na função de diplomata, a diplomacia sendo um mundo formado por pequenas cortesias e etiquetas:

Como seja, depois da cerimônia oficial de instalação a que eu assistira trajando uniforme ao lado dos meus colegas da Bélgica e da Itália (os outros cônsules, cometendo uma falha de etiqueta, usavam uma simples sobrecasaca, o que foi bastante observado), julguei bem fazer, em companhia de uma delegação da Colônia, uma visita de cortesia e de parabenização ao Palácio à qual o presidente se mostrou ainda mais sensível na medida em que nenhuma outra Colônia Estrangeira havia tomado tal iniciativa ${ }^{42}$.

38 Rio de Janeiro, carta do chargé de mission ao ministro das Relações Exteriores Marcellin Berthelot. AMAE, Brésil. Politique intérieure. Immigration, v. I, 24/3/1896, f. I06.

39 DELGADO, L. de A.; FERREIRA, J., op. cit.

40 São Paulo, carta do cônsul Georges Ritt ao ministro das Relações Exteriores Gabriel Hanotaux. AMAE, Brésil.

Politique intérieure. Immigration, v. I, 23/4/1896, f. п10.

4 I Ibidem.

42 São Paulo, carta do cônsul Georges Ritt ao ministro das Relações Exteriores Gabriel Hanotaux. AMAE, Brésil.

Politique intérieure. Immigration, v. I, 3/5/1896, f. II6. 
De maneira geral, os diplomatas buscam lançar um alerta ao Ministério das Relações Exteriores francês sobre tudo aquilo que lhes parece perturbar a estabilidade do regime brasileiro, no caso, a República recém-instalada. Assim, o ministro plenipotenciário Stephen Pichon, talvez em sua primeira correspondência na função, em 8 de maio de I886, busca resumir as manifestações políticas da "quinzena que acaba de passar". Com uma caligrafia de difícil leitura, ele alerta para o fato de que "os principais representantes da opinião monarquista fundaram um jornal diário no Rio"33 para criticar o governo depois da "Revolução de I889", cujo título era Liberdade. Porém, como acrescenta, a tranquilidade pública vigora: "Desde já, podemos nos assegurar de que a campanha monarquista não constitui perigo algum para a República"44.

Em outra carta, datada de 6 de junho de I896, o mesmo ministro plenipotenciário Stephen Pichon indaga sobre o futuro do federalismo brasileiro e a vontade do presidente Prudente de Morais de reforçar o poder da União sobre os estados, os quais, porém, estão “decididos a não se deixarem despossuir de seus direitos" 45 . A mudança constitucional desejada por Prudente de Morais não se concretizava, na realidade, pois havia

[...] uma dificuldade de conciliar os costumes, os hábitos do norte com os do centro, do sul do leste e do oeste, em um país onde o clima, a natureza, a história e as tradições são tão variadas. Existe um perigo para a manutenção da União, um modo de ação para o separatismo. A verdade seria talvez um meio-termo entre o extremo federalismo e a centralização ${ }^{46}$.

\section{Um simulacro de República}

De uma conduta geral de observação sobre o bom comportamento da República brasileira no final do século XIX e primeiros anos do novo regime, uma década mais tarde, os novos diplomatas franceses passam a ser, por sua vez, bem mais críticos. Esse é o caso, por exemplo, das correspondências que relatam o contexto das eleições para a Presidência da República de I9Io, consideradas como um tempo de ameaça de ruptura na estabilidade do "pacto republicano eleitoral", até então garantido por uma alternância de poder limitada, construída e negociada pelos principais estados da federação, como São Paulo e Minas Gerais, em primeiro lugar, mas também Bahia,

43 Rio de Janeiro, carta do ministro plenipotenciário Stephen Pichon ao ministro das Relações Exteriores Gabriel Hanotaux. AMAE, Brésil. Politique intérieure. Immigration, v. I, 8/5/1886, f. II9.

44 Ibidem.

45 Rio de Janeiro, carta do ministro plenipotenciário Stephen Pichon ao ministro das Relações Exteriores

Gabriel Hanotaux. AMAE, Brésil. Politique intérieure. Immigration, v. I, 6/6/I886, f. I4I.

46 Ibidem. 
Pernambuco, Rio Grande do Sul e Rio de Janeiro, a fim de manter no poder as mesmas oligarquias ${ }^{4}$.

Em uma correspondência do dia Iํo de agosto de I909, o correspondente da França no Brasil M. Lacombe escreve ao ministro para fazer algumas observações sobre o sistema político local. Sua visão é bastante negativa:

Sua excelência não ignora que não existem partidos políticos propriamente ditos no Brasil. Diferentes personalidades atraem para si clientes mais ou menos numerosos, tomam o poder nos municípios e nos estados, introduzem nos corpos representativos seus homens, colocam suas criaturas nas funções públicas e, dessa forma, exercem uma autoridade oculta. Eles são os chefes políticos ${ }^{4}$.

Um ano antes, numa carta de 28 de agosto de 1908 sobre a sucessão presidencial, o representante francês no Rio, $M$. Lacombe, comenta o perfil dos dois candidatos, Hermes da Fonseca, marechal do Exército, representante do lado "militarista", e Rui Barbosa, jurista, intelectual e humanista, representante da candidatura chamada "civilista”. Sobre Hermes da Fonseca, ele escreve:

No que nos concerne, não teremos, creio, motivos para nos alegrar com a eleição do marechal Hermes. Este último declarou a alguém, para que isto me fosse relatado, que ele não era teria melhor disposição para os alemães ou para os franceses, e ele representa no Exército a influência germânica, influência cuja fonte e força eu fiz conhecer nos meus relatórios precedentes. É de temer que ele confie a questão da instrução do Exército, caso ele a resolva a princípio, a oficiais do imperador Guilherme. Militar ambicioso, sem nenhum valor político, ele seria o porta-voz dos homens que o colocaram no poder e sua administração poderia ser nefasta às forças econômicas do país que nos interessam a um grau bastante elevado como credor ${ }^{49}$.

Vê-se através dessa passagem que a análise dos diplomatas franceses estava frequentemente influenciada pelos interesses do lugar da França na nova ordem geopolítica mundial, bem como por seus interesses econômicos ligados às classes dominantes locais. As decisões políticas brasileiras eram interpretadas nesse

47 Essa aliança entre estados para garantir a permanência no poder das mesmas oligarquias em momentos de alternância era conhecida, pela historiografia tradicional, como política do "café com leite”. Novos trabalhos revisam esse conceito, pois, se havia conchavos entre estados para manter as oligarquias, eles iam muito além da aliança exclusiva entre Minas e São Paulo, sempre com o mesmo objetivo de construir uma república excludente, uma cidadania limitada pois sem direitos sociais e com uma participação política ultralimitada. Ver: VISCARDI, C., op. cit; ENDERS, A. Pour en finir avec la politique du café au lait: État fédéral, intérêts régionaux et intérêts du café sous la Première République (I889-I930). Cahiers du Brésil Contemporain, n. I9, I992, p. 69-9I

48 Rio de Janeiro, carta do chargé de mission Lacombe ao ministro das Relações Exteriores Stephen Pichon. AMAE, Correspondance politique et commerciale, politique Intérieure - Immigration,v. V, I/8/I909.

49 Rio de Janeiro, carta do chargé de mission Lacombe ao ministro das Relações Exteriores Stephen Pichon. AMAE, Correspondance politique et commerciale, politique Intérieure - Immigration, v. IV, 28/8/1908. 
contexto de disputas europeias, em que a Alemanha constituía o maior inimigo francês.

As eleições de I9Io iriam ser marcadas por uma ruptura dos pactos tradicionais e uma aliança, contra os outros estados, entre São Paulo e Rio de Janeiro em torno da candidatura de Rui Barbosa, e com certa mobilização popular, o que era raro no contexto. Sobre Rui Barbosa, o mesmo diplomata diz:

Ele passa por ser um jurisconsulto eminente, mas, se admiramos sua ciência e sua erudição, sabemos também que ele é de caráter frágil e pouco capaz de realizar o que concebe e empreende. A julgar por seus planos financeiros tão miseravelmente abortados em I89o e cujas consequências pesam ainda hoje sobre o Brasil. Poderíamos também taxá-lo de utópico ${ }^{50}$.

Essa imagem de Rui Barbosa, homem fraco e quiçá incompetente, em referência aos seus feitos como ministro da Fazenda no início da República (I889-I89I), quando foi considerado responsável pela política econômica que gerou uma corrida inflacionária conhecida como "encilhamento", é bem distante da imagem do intelectual e jurista Rui Barbosa que se construiu no Brasil: ativo na questão abolicionista e na Proclamação da República ${ }^{51}$.

O representante francês não toma abertamente nenhum partido nessas eleições. As duas candidaturas seriam, aos olhos de Lacombe, problemáticas. Hermes, do ponto de vista político, e Rui, do ponto de vista financeiro, como diz mais adiante na carta, depositando suas esperanças "nas capacidades dos ministros do futuro governo". Ele termina a comparação revelando um ponto comum aos dois candidatos, segundo ele, uma característica dos brasileiros em geral: o desejo de aparecer! Em carta de 28 de agosto de I909: "No entanto, todos os dois têm, aos olhos de seus compatriotas, reforçado o prestígio exterior de seu país e, qualquer que seja o fundamento desse julgamento, não é menos simbólico do traço dominante da personalidade brasileira: aparecer!"52.

A candidatura civilista (Rui Barbosa), até mesmo por ser mais frágil do ponto de vista das alianças, mobilizou vários setores populares, principalmente nas grandes cidades e no Rio de Janeiro. Algumas de suas promessas eram a reforma do sistema eleitoral (com o voto secreto), o incentivo à educação básica e o estímulo à imigração. Do outro lado, Hermes agradava os militares com sua lei do "sorteio militar", dentre outros aspectos ${ }^{53}$.

Mas o processo político brasileiro em si era bastante criticado pelos

50 Rio de Janeiro, carta do chargé de mission Lacombe ao ministro das Rlações Exteriores Stephen Pichon.

AMAE, Correspondance politique et commerciale, politique Intérieure - Immigration, v. V, Io/2/I9Io.

5 I ALONSO, A. Flores, votos e balas. O movimento abolicionista brasileiro (I868-88). São Paulo: Companhia das Letras, 20I5; SILVA, E. As camélias do Leblon e a abolição da escravatura: uma investigação de história cultural. São Paulo: Companhia das Letras, 2003.

52 Rio de Janeiro, carta do chargé de mission Lacombe ao ministro das Relações Exteriores Stephen Pichon. AMAE, Correspondance politique et commerciale, politique Intérieure - Immigration, v. V, 28/8/1909.

53 Ver: CAPANEMA P. DE ALMEIDA, S. “Nous, marins, citoyens brésiliens et républicains?...”, op. cit. 
correspondentes franceses, o que dialoga com a imagem de República excludente que a Primeira República tem na história do Brasil. Assim, o correspondente francês Lacombe escreve, no dia Io de fevereiro de I9IO:

Para apreciar tais eleições não se pode esquecer que a federação brasileira constitui na realidade um sindicato de pequenas oligarquias: na maior parte dos estados, onde a civilização é ainda superficial, os chefes políticos exercem uma autoridade bastante incontestada, e dispõem da quase totalidade dos votos, que os eleitores podem, de acordo com suas necessidades, se dispensar de exprimir. O presidente da República elege-se dessa feudalidade: de acordo com ela, ele designa seu sucessor e coloca a serviço da candidatura oficial todos os meios de ação governamental. Um simulacro de eleição vem em seguida sancionar essa escolha ${ }^{54}$.

Essas observações são evidentemente o olhar dos diplomatas franceses sobre um fragmento da República no Brasil. Porém, como a França era o modelo de República para os brasileiros, parecer um "simulacro" aos olhos dos diplomatas franceses significaria, de certa forma, distanciar-se também do projeto que se pretendia para o país.

Os diplomatas franceses, ao representar o Brasil em suas correspondências, participam da construção da Primeira República brasileira como um projeto que ultrapassa as fronteiras nacionais. Vivem em um mundo onde as relações internacionais são mobilizadas pela circulação de ideias, de impressos, de escritos, mas também de pessoas e atores sociais, numa relação entre dois ou vários polos, mesmo que haja assimetrias e que os franceses busquem exercer, o máximo que podem, sua predominância cultural, econômica e política. De maneira geral, nas fontes estudadas, os correspondentes franceses criticam a República brasileira tanto pela ausência de participação popular - crítica frequente na imprensa da época e que já se tornou um lugar-comum da historiografia brasileira ${ }^{55}$-, como também pela possível instabilidade do regime. Essa falta de estabilidade poderia ser nociva aos interesses da potência europeia no Brasil. A República brasileira não inspirava confiança - quer com relação ao seu sistema político, quer como terra atrativa para a imigração - pois parecia ser um regime de desordem e distante da modernidade europeia ou ocidental. Um mundo em que práticas herdadas da escravidão permaneciam, bem como uma democracia deficiente. Dessa forma, vista através do espelho das representações da correspondência de diplomatas que pertenciam a diferentes correntes do republicanismo francês, a República brasileira parecia desfocada, irreconhecível, o inverso de um dos sistemas que pretendia refletir.

54 Rio de Janeiro, carta do chargé de mission Lacombe ao ministro das Relações Exteriores Stephen Pichon. AMAE, Correspondance politique et commerciale, politique Intérieure - Immigration, v. V, Io/2/I9IO.

55 Entre outros trabalhos já citados, ver também esta crítica da República elitista e da ausência de "povo" através da caricatura: SILVA, M. A. A caricata República: Zé Povo e o Brasil. São Paulo: CNPq-Marco Zero, I99o. 


\section{SILVIA CAPANEMA P. DE ALMEIDA é doutora em}

História pela École des Hautes Études en Sciences

Sociales (EHESS), professora adjunta da Université

Paris I3 - Sorbonne Paris Cité e pesquisadora

de Pléiade (EA 7338).

E-mail: silvia.capanema@gmail.com

\section{REFERÊNCIAS BIBLIOGRÁFICAS}

ALONSO, A. Flores, votos e balas. O movimento abolicionista brasileiro (I868-88). São Paulo: Companhia das Letras, 2015 .

CAPANEMA P. DE ALMEIDA, S. “Nous, marins, citoyens brésiliens et républicains?”: identités, modernité et mémoire de la révolte des matelots de I9Io. Tese (Doutorado em História). École des Hautes Études en Sciences Sociales. Paris, 2009.

. A modernização do material e do pessoal da Marinha nas vésperas da revolta dos marujos de I9IO: modelos e contradições. Estudos Históricos, Rio de Janeiro, v. 23, p. I47-I69, 2010.

CAPANEMA, S.; COMPAGNON, O.; FLECHET, A. Os franceses não tomam banho? Imagens e imaginário da França no Brasil (séculos XIX-XXI). Rio de Janeiro: Fundação Casa de Rui Barbosa/7 Letras, 20I7 (no prelo).

CARVALHO, J. M. de. Os bestializados: o Rio de Janeiro e a República que não foi. São Paulo: Companhia das Letras, I987.

COSTA, E. V. da. Da monarquia à república - momentos decisivos. São Paulo: Unesp, I999. . Da senzala à colônia. São Paulo: Unesp, I998.

DELGADO, L. de A; FERREIRA, J. (Org.). O Brasil republicano. Volume I. O tempo do liberalismo excludente: da Proclamação da República à Revolução de I930. Rio de Janeiro: Civilização Brasileira, 2006,

DUCLERT, V. La République imaginée - I870-I9I4. Paris: Belin, 2010.

DUMONT, J. Le Brésil et l'Institut International de Coopération Intellectuelle (I924-I946): le pari de la diplomatie culturelle. Paris: Éditions de l'IHEAL, 2009.

ENDERS, A. Pour en finir avec la politique du café au lait: État fédéral, intérêts régionaux et intérêts du café sous la Première République (I889-I930). Cahiers du Brésil Contemporain, n. I9, I992, p. 69-9I.

EVEN, P. Guide des sources de l'histoire du Brésil aux archives du ministère français des affaires étrangères. Paris: Editions de l'IHEAL, I987.

FRANCE Diplomacie. Centre des Archives Diplomatiques de La Courneuve. Disponível em: <http://www. diplomatie.gouv.fr/fr/archives-diplomatiques/acceder-aux-centres-des-archives-diplomatiques/sitede-paris-la-courneuve>. Acesso em: I2 jun. 20I7.

FRANK, R. Images, imaginaire et Europe: présentation. In: GIRAULT, R. (Dir.). Identité et conscience européennes au XXe siècle. Paris: Hachette, I994.

. Altérité, représentations de l'Autre. In: DELPORT, C.; MOLIER, J.-Y.; SIRINELLI, J.-F. (dir.). Dictionnaire d'histoire culturelle de la France contemporaine. Paris: PUF, 2010. 
LESSA, M. L.; SUPPO, H. R. A emigração proibida: o caso França-Brasil entre I875 e I908. In: LUCA, T. R. de; VIDAL, L. (Org.). Franceses no Brasil: séculos XIX-XX. São Paulo: Unesp, 2009, p. 67-I03.

LESSA, R. A invenção republicana: Campos Sales, as bases e a decadência da Primeira República brasileira. 3. ed. revista e aumentada. Rio de Janeiro: Top Books, 2015.

LUCA, T. R. de; VIDAL, L. (Org.). Franceses no Brasil: séculos XIX-XX. São Paulo: Unesp, 2009.

MATTOS, H. A vida política. In: SCHWARCZ, L. M. (Dir.). História do Brasil nação. A abertura para o mundo, I889-I930. Rio de Janeiro: Objetiva, 20I2, p. 84-I3I.

MELLO, M. T. C. A República consentida: cultura democrática e científica no final do Império. Rio de Janeiro: FGV-Editora da UFRJ, 2007.

MONTEIRO, C. A. S. France et Brésil: de l’Empire à la République (I850-I89I). Tese (Doutorado em História). Strasbourg, Université Robert Schuman, 2006.

PONCIONI, C. Pontes e ideias - Louis-Léger Vauthier, um engenheiro fourierista no Brasil. Recife: Companhia Editora de Pernambuco, 2010.

REBERIOUX, M. La République radicale? I898-I9I4. Paris: les éditions du Seuil, I975. (Coll. Points Histoire.) RAYMOND, J.-F. de (Org.). Arthur de Gobineau et le Brésil: correspondance diplomatique du ministre de France à Rio de Janeiro, I869-I870. Grenoble: Presses Universitaires de Grenoble, I990.

SILVA, E. As camélias do Leblon e a abolição da escravatura: uma investigação de história cultural. São Paulo: Companhia das Letras, 2003.

SILVA, M. A. A caricata República: Zé Povo e o Brasil. São Paulo: CNPq-Marco Zero, I990.

VISCARDI, C. O teatro das oligarquias: uma revisão da "política do café com leite". Belo Horizonte: C/ Arte, 200I. 